\title{
High-Temperature Kinetic Study for the Reactive Ion Etching of InP in $\mathrm{BCl}_{3} / \mathrm{Ar} / \mathrm{O}_{2}$
}

\author{
Alex T. Demos and H. Scott Fogler \\ Dept. of Chemical Engineering, University of Michigan, Ann Arbor, MI 48109 \\ Jeffrey Fournier and Michael E. Elta \\ Dept. of Electrical Engineering and Computer Science, University of Michigan, Ann Arbor, MI 48109
}

\begin{abstract}
The reactive ion etching kinetics of InP studied uses $B C l_{3} / \mathrm{Ar}$ and $\mathrm{BCl}_{3} / \mathrm{Ar} / \mathrm{O}_{2}$ as etchants. High-temperature etching using $\mathrm{BCl}_{3}$ and Ar increases the etch rate negligibly. However, the addition of $30 \%$ oxygen in the gas feed increases etch rates by a factor of 10,000 up to 1.5 micron/min at wafer temperatures of $250^{\circ} \mathrm{C}$. X-ray photoelectron spectroscopy analysis reveals that oxygen removes the boron species adsorbing on the InP surface by scavenging the boron to form volatile boron oxides. To study the gas-phase chemistry, optical emission spectroscopy is used to monitor atomic chlorine intensity at different gas mixtures. The chlorine intensity shows a Gaussian-type dependence with oxygen addition, which is similar to the etch rate dependence. Two regimes of etching found are: at temperatures below $150^{\circ} \mathrm{C}$, the etching is limited by the removal of indium chlorides; above $180^{\circ} \mathrm{C}$, the etching is reaction-limited. The surface morphology shows that the etch profile becomes rougher as a result of increased chemical etching. At high power densities $\left(0.21 \mathrm{~W} / \mathrm{cm}^{2}\right)$ and intermediate temperatures $\left(150^{\circ} \mathrm{C}\right)$, near vertical wall shapes are obtained. A kinetic model for the high-temperature etching is developed, as well as a rate law based on the InCl formation reaction. The rate law compares favorably with experimental etch rate results.
\end{abstract}

\section{Introduction}

The ability to etch InP in a controllable manner is necessary for fabricating optoelectronic devices. The ideal process would combine the benefits of both chemical etching and sputter etching. Chemical etching at high wafer temperatures produces high etch rates with isotropic profiles, while sputter etching produces lower etch rates with anisotropic profiles and with smooth morphology. The etching of InP has been performed in plasma systems using chlorine-based gases and hydrocarbon gases. With chlorine, high wafer temperatures are required to remove nonvolatile indium chlorides (Donnelly et al., 1982). In recent work, $\mathrm{CH}_{4} / \mathrm{C}_{2} \mathrm{H}_{6} / \mathrm{H}_{2}$ gas mixtures have been used; however, low etch rates and polymer deposition are a problem with hydrocarbon gases (Hayes et al., 1988, 1989). $\mathrm{BCl}_{3} / \mathrm{Cl}_{2}$ gas mixtures have been used to etch Group III-V semiconductors, primarily GaAs and aluminum (Contolini, 1988; Sonek and Ballantyne, 1984; Coop-

Correspondence concerning this article should be addressed to H. S. Fogler. erman et al., 1989). $\mathbf{B C l}_{3}$ is a useful gas since it scavenges water and oxygen (Hess, 1982).

There have been three high-temperature etching studies for InP in chlorine plasmas and each study has given different results. The first study used $\mathrm{CCl}_{4}$ to etch InP. It found that by increasing wafer temperatures there was a dramatic decrease in etch rates (Gottscho et al., 1982). This decrease was attributed to the carbon contamination at the wafer surface at high temperatures. A second study used chlorine to etch InP. It found that the activation energy was near 35 $\mathrm{kcal} / \mathrm{mol}$, which is significantly higher than that reported here (Donnelly et al., 1982). The reason for the difference in activation energies is that our experiments were performed in a reactive ion etching (RIE) apparatus that contains ion bombardment to the surface, whereas in the previous study, a plasma system with a pressure of 300 mtorr was used with low power densities. Without ion bombardment, a higher activation energy would result, because chemical etching would 
be dominant. A third study related to this work focused on the etching of InP in a RIE environment with chlorine and argon (Contolini, 1988). This study found that there was a decrease in etch rate as the temperature increased from 50 to $190^{\circ} \mathrm{C}$, and that the argon ions bombarded the surface and removed the chlorine atoms before the surface reaction could take place. A graphite cathode was used in this study, and it may have been possible that contamination of the wafer took place due to carbon backsputtering. Another drawback to using a graphite cathode is that scavenging of the chlorine by carbon atoms can occur.

The work presented in this article focuses on the high-temperature etching of InP using $\mathrm{BCl}_{3}$ and argon. The role of oxygen addition was very important and greatly affected the etch rate. With the addition of dilute amounts of oxygen, large etch rate increases were obtained. However, with excess amounts of oxygen the etch rate approached zero. Therefore, the role of oxygen was investigated for different flow mixtures. The kinetics of this system were studied and a mechanism was postulated for InP etching. At low temperatures, etching appears to be desorption limited, while at high temperatures, surface reaction limits the etch rate. In addition, the surface composition and gas-phase chemistry were analyzed through XPS and optical emission spectroscopy, respectively. Finally, the suitability of this etching system was evaluated in terms of anisotropic etching and surface morphology.

\section{Experimental}

The InP samples etched were (100) in orientation, Fedoped, and grown by CrystaComm, Inc. The samples were masked with 2,000 $\AA$ of nickel and etch depths were determined by surface profilometry using a Sloan Dektak II. The etch experiments were performed in an industrial SemiGroup RIE $1000 \mathrm{TP} / \mathrm{CC}$ using a RF power supply operated at $13.56 \mathrm{MHz}$. A Techware Process Automation Controller (PAL) was used to automate the entire etch process.

High wafer temperatures up to $400^{\circ} \mathrm{C}$ were obtained using a heated stage with heating coils built into the bottom electrode. Wafer temperatures were monitored with a thermocouple located in the cathode and the temperature was controlled with a Watlow 842 temperature controller. Actual wafer temperatures were calibrated before etching with temperature tape sensors. An offset of $25^{\circ} \mathrm{C}$ was added to the thermocouple temperatures to compensate for thermocouple contact problems at high vacuum conditions. The wafer heating from ion energy was neglected in this work.

The XPS experiments were performed in a Perkin Elmer PHI 5400 ESCA system. A Mg K alpha monochromatic source $(1,253.6 \mathrm{eV})$ was used with an input power of $300 \mathrm{~W}$. Survey spectra and high-resolution spectra were obtained in a constant analyzer mode at 178.95 and $71.55 \mathrm{eV}$, respectively. Data were collected in $1 \mathrm{eV}$ increments, $50 \mathrm{~ms} /$ increment, for 50 scans in the survey mode and $0.10 \mathrm{eV}$ increments, $50 \mathrm{~ms} / \mathrm{in}-$ crement, for 50 scans in the high-resolution mode. The surface composition of the InP was determined after etching by XPS using an angle of $45^{\circ}$ between the electron analyzer and the wafer surface.

The optical emission system consisted of a quartz fiber optic cable that gathers light from the plasma and illuminates

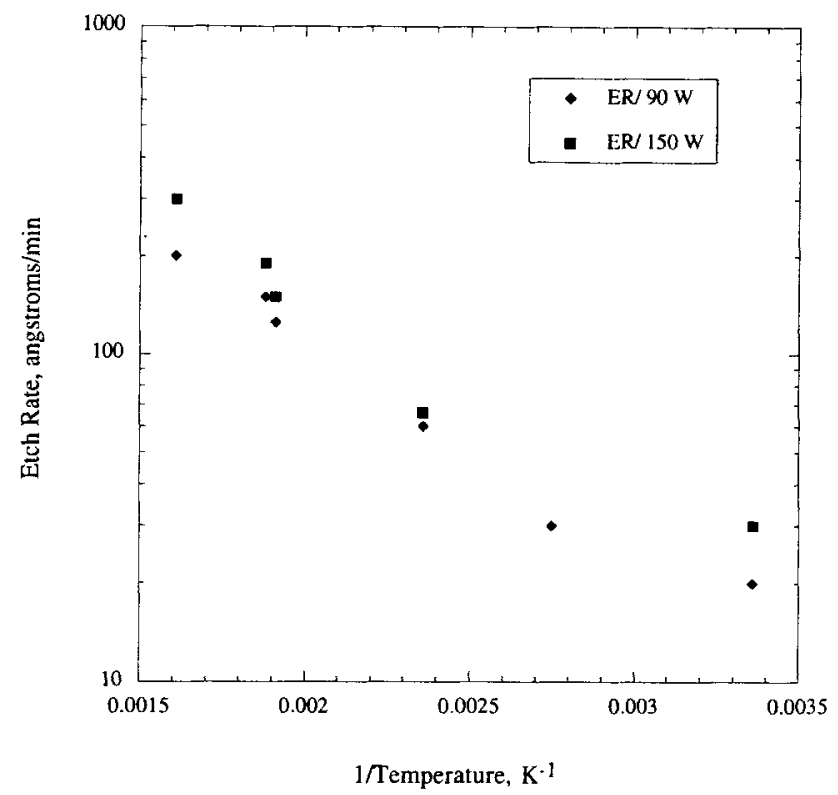

Figure 1. InP etch rate vs. temperature for RIE conditions: 12 std. $\mathrm{cm}^{3} \mathrm{BCl}_{3}$ and 8 std. $\mathrm{cm}^{3}$ Ar flow, and pressure of $\mathbf{4 0}$ mtorr and RF power of $\mathbf{9 0}$ and $150 \mathrm{~W}$.

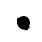

the entrance slit of an EG\&G 1233, 0.275-m spectrograph with interchangeable gratings. An EG\&G 1024 photodiode array detector digitized the light intensity from the spectrograph. The detector was controlled by an EG\&G PARC model 1460 OMA III. This system provided spectral emission as a function of wavelength.

\section{Results and Discussion $\mathrm{BCl}_{3} / \mathrm{Ar}$ etching results}

The initial etch experiments were carried out using only $\mathrm{BCl}_{3}$ and argon at high wafer temperatures up to $350^{\circ} \mathrm{C}$. It was anticipated that these gases would produce enhanced etching because the indium chlorides are desorbed at higher temperatures (Donnelly et al., 1982). An Arrhenius plot of the InP etch rate vs. temperature is shown in Figure 1 for the RIE etching parameters of gas flows of $12 \mathrm{sccm} \mathrm{BCl}_{3}$ and 8 sccm argon, pressure of 40 mtorr and RF power of $90 \mathrm{~W}$ $\left(0.13 \mathrm{~W} / \mathrm{cm}^{2}\right)$ and $150 \mathrm{~W}\left(0.21 \mathrm{~W} / \mathrm{cm}^{2}\right)$. The DC bias voltages for these two power densities were -215 and $-400 \mathrm{~V}$, respectively. Oxygen was not added to the gas flow for these experiments.

Figure 1 shows that the etch-rate enhancement was minimal, with etch rates of only $300 \AA / \mathrm{min}$ obtained at $350^{\circ} \mathrm{C}$. Etches using different etching parameters such as high power and low pressure were also performed, but these different parameters did not substantially increase etch rates. One explanation for the low etch rates is that an inhibiting film formed on the InP surface. Surface analysis (see the section titled "X-ray photo electron spectroscopy surface analysis") showed that boron coverage occurred when using the $\mathrm{BCl}_{3}$ and argon gas mixture. Another reason for the low etch rates is that the etching was chlorine flux limited, and the chlorine concentration might not have been sufficiently high. Optical 


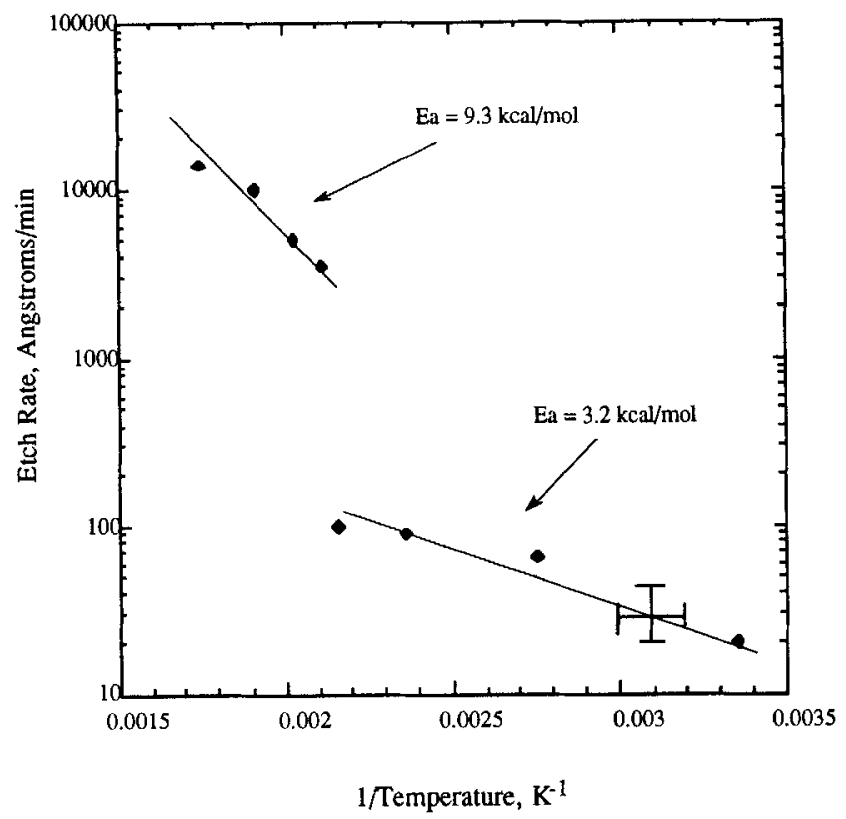

Figure 2. InP Arrhenius plot for etching at 12 std. $\mathrm{cm}^{3}$ $\mathrm{BCl}_{3}$ and $8 \mathrm{std} . \mathrm{cm}^{3} \mathrm{Ar} \mathbf{s c c m}, 40$ mtorr pressure and 90-W RF power.

emission was performed to verify this possibility and these results are presented in the section titled "Optical emission."

\section{Oxygen addition}

A few preliminary results suggested that the etch rate would increase if oxygen was added to the gas flow since oxygen is useful in removing impurities such as carbon and boron (Cooperman et al., 1989). In addition, when oxygen is added to $\mathrm{BCl}_{3}$, the atomic chlorine concentration can increase through gas-phase reactions. With $16 \%$ oxygen added to the base case RIE parameters (cf. Figure 1), an etch rate of $8,000 \AA / \mathrm{min}$ was obtained at $220^{\circ} \mathrm{C}$. At $280^{\circ} \mathrm{C}$, an etch rate of $1.6 \mu \mathrm{m} / \mathrm{min}$ was obtained. By using an Arrhenius-type expression for the etch rate shown in Eq. 1, the temperature dependence can be studied.

$$
R_{\text {etch }}=A \exp \{-E a / R T\} f(\mathrm{Cl}, \mathrm{Ar})
$$

where $E a$ is the activation energy $(\mathrm{kcal} / \mathrm{mol} \cdot \mathrm{K}), A$, a preexponential factor $(\AA / \mathrm{min}) ; R$, the gas constant $(1.987 \mathrm{cal} / \mathrm{mol}$ $\cdot \mathrm{K}) ; T$, the absolute surface temperature $(\mathrm{K})$; and $f(\mathrm{Cl}, \mathrm{Ar})$ represents the chlorine-neutral and argon-ion dependence on etch rate.

Arrhenius plots of $\ln$ (etch rate) vs. $1 / T$ are shown in Figures 2 and 3 for the two power densities used (0.13 and 0.21 $\mathrm{W} / \mathrm{cm}^{2}$ ), with dilute oxygen added. Although the two curves are similar in behavior, the etching at $150 \mathrm{~W}$ produced high etch rates above $180^{\circ} \mathrm{C}$, whereas at $90 \mathrm{~W}$, high etch rates were produced above $200^{\circ} \mathrm{C}$. The reason high etch rates were initiated at $180^{\circ} \mathrm{C}$ at the higher power density was that ion-assisted etching mechanisms such as sputter desorption increase the etch rate by physically removing indium chloride. Therefore, both power and temperature can be viewed as

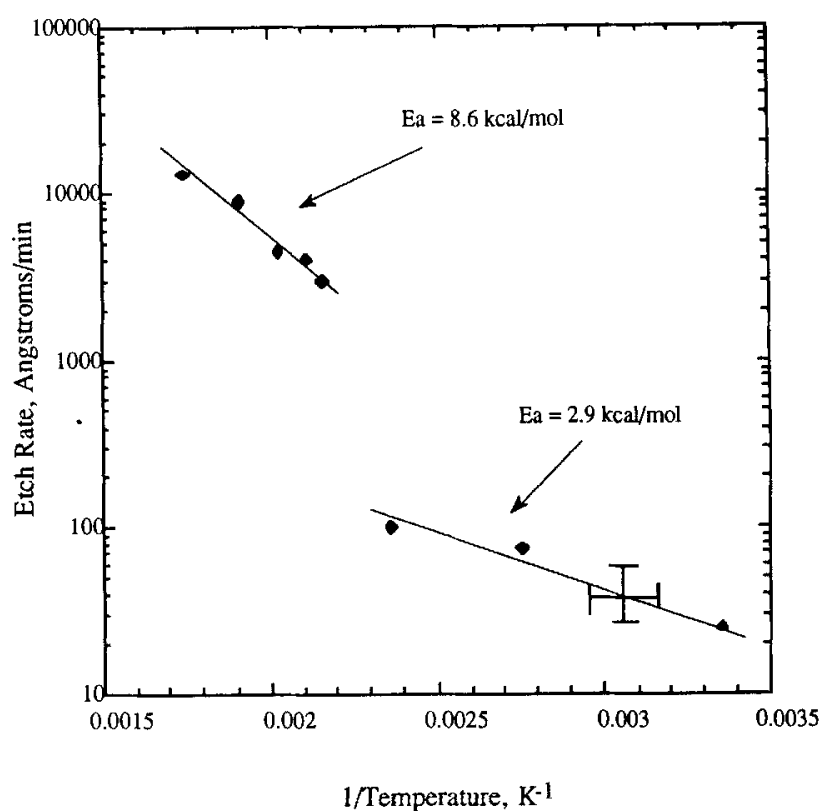

Figure 3. InP Arrhenius plot for etching at $12 \mathrm{std} . \mathrm{cm}^{3}$ $\mathrm{BCl}_{3}$ and 8 std. $\mathrm{cm}^{3}$ Ar std. $\mathrm{cm}^{3}, 40$ mtorr pressure and $150-W$ RF power at $250^{\circ} \mathrm{C}$.

complementary variables, where high RF power produces high wafer temperatures due to ion heating.

In the Arrhenius plots of Figures 2 and 3, there appears to be two regimes of etching as shown by the two linear portions. The transition temperature for etching at $90 \mathrm{~W}$ was near $200^{\circ} \mathrm{C}$. The activation energies were calculated from the slope of the linear portions of the Arrhenius plots. The regime below $200^{\circ} \mathrm{C}$ gave an activation energy near $3 \mathrm{kcal} / \mathrm{mol}$, and the regime above $200^{\circ} \mathrm{C}$ gave an activation energy near 9 $\mathrm{kcal} / \mathrm{mol}$. The transition temperature for the etching at 150 W was near $180^{\circ} \mathrm{C}$ and the activation energies were also calculated to be 3 and $9 \mathrm{kcal} / \mathrm{mol}$ for the regimes below and above $180^{\circ} \mathrm{C}$, respectively.

For our high-temperature study there appear to be two different etching regimes, as evidenced by the different slopes shown in the Arrhenius plots. In the low-temperature regime, the removal of indium chlorides from the surface may limit the etch rate. In the high-temperature region, etching may be chlorine flux limited or limited by surface reaction.

The effect of adding oxygen to different $\mathrm{BCl}_{3} / \mathrm{Ar}$ flow mixtures is shown in Figure 4. The etch rate increased by a factor of 10,000 with the addition of oxygen. The position of the maximum peak and the magnitude of the etch rate shifted for the different flow conditions. One observes an etch-rate increase by a factor of 10,000 times with the addition of oxygen. For the condition of $8 \mathrm{sccm} \mathrm{BCl}_{3}$ and $12 \mathrm{sccm}$ Ar flow, the maximum etch rate was at $23 \%$ oxygen. For the flow of 12 std. $\mathrm{cm}^{3} \mathrm{BCl}_{3}$ and $8 \mathrm{sccm} \mathrm{Ar}$, the maximum etch rate was near $33 \%$ and for the flow of $15 \mathrm{std} . \mathrm{cm}^{3} \mathrm{BCl}_{3}$ and $5 \mathrm{sccm}$ Ar, the maximum etch rate was near $40 \%$. The three curves in Figure 4 contain an optimum oxygen flow where etching was maximum, and the curves also show the trend of low etch rates at both high and low oxygen flow rates. To explain these results both the gas-phase and gas-solid chemistry needed to be examined. 


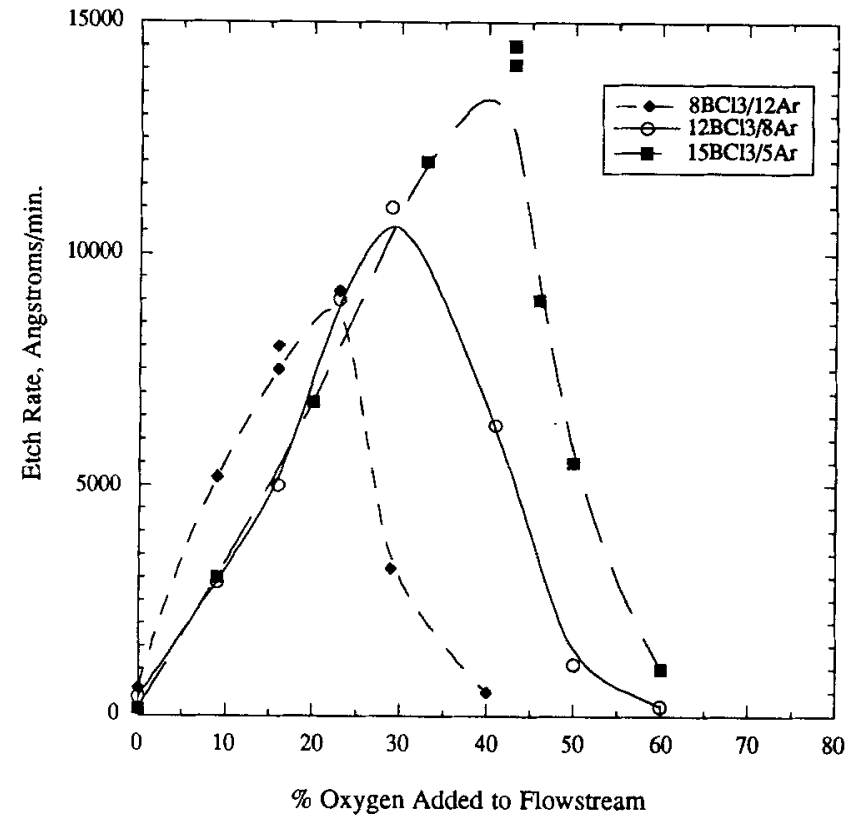

Figure 4. Effect of oxygen addition for different $\mathrm{BCl}_{3} / \mathrm{Ar}$ gas mixtures on $\operatorname{InP}$ etch rate at $250^{\circ} \mathrm{C}$.

At high temperatures and high oxygen concentrations, a white powder coated the reactor walls, cathode, and InP. Figure 5 shows a SEM photograph of InP etched using a high oxygen concentration. This powder was found to be $\mathrm{B}_{2} \mathrm{O}_{3(s)}$ which is a rhombic crystalline structure and can be seen in the SEM. The chamber was cleaned with a wet cloth after etching to remove the boron oxide since $\mathrm{B}_{2} \mathrm{O}_{3(s)}$ is hydrolyzed in water to form boric acid (Dean, 1985). As mentioned, the maximum etch rate peak shifted with increasing $\mathrm{BCl}_{3}$ flow. An oxygen/boron atomic ratio was calculated from the flow rates in Figure 4, yielding an atomic ratio between 1.6 to 1.8 for the three different $\mathrm{BCl}_{3}$ flow conditions. It is interesting to note that for $\mathrm{B}_{2} \mathrm{O}_{3(s)}$ the atomic ratio of oxygen/boron is 1.5 . Therefore as Figure 4 shows, when etching

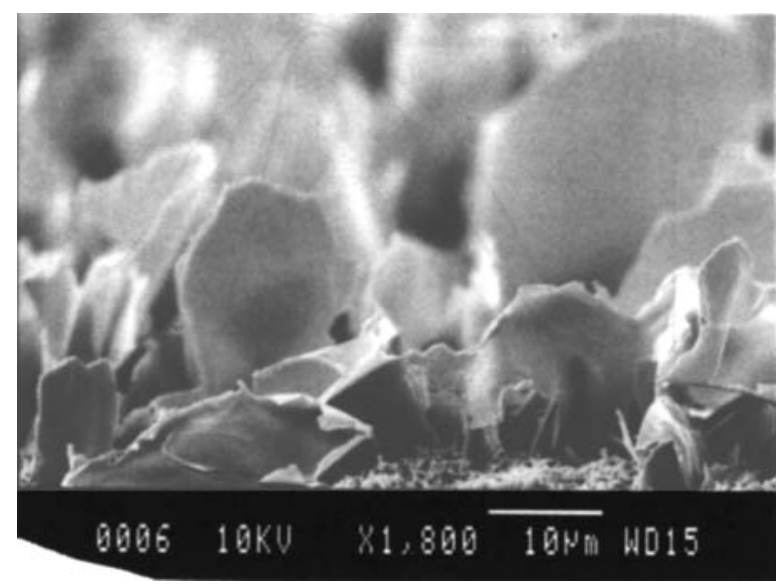

Figure 5. SEM photo of InP etched with $\mathrm{BCl}_{3} / \mathrm{Ar}$ and excess oxygen.

Boron oxide rhombic structure is evident. at the maximum etching condition, any increase in oxygen flow would translate into a decrease in etch rate due to the formation of $\mathrm{B}_{2} \mathrm{O}_{3(s)}$.

One observes from Figure 4 that the etch-rate peaks shifted to the right with increased $\mathrm{BCl}_{3}$ flows, indicating that more oxygen was required for etching. Results of the surface analysis in the following section will show that without oxygen, boron contamination on InP was taking place. At high $\mathrm{BCl}_{3}$ flow rates, more boron formed on the InP and additional oxygen was required to remove the boron. Figure 4 also shows that the magnitude of the etch-rate peaks also increased with increased $\mathrm{BCl}_{3}$ flow. With $15 \mathrm{sccm} \mathrm{BCl}_{3}$ and 5 std. $\mathrm{cm}^{3} \mathrm{Ar}$ flows, the maximum etch rate was near $1.5 \mu \mathrm{m} / \mathrm{min}$, whereas with 8 std. $\mathrm{cm}^{3} \mathrm{BCl}_{3}$ and 12 std. $\mathrm{cm}^{3}$ Ar flows, the maximum etch rate was $0.9 \mu \mathrm{m} / \mathrm{min}$. This trend can be explained by looking at the chlorine neutral concentration. At high $\mathrm{BCl}_{3}$ flows more chlorine is available for reaction to give the high etch rates. The optical emission results in the section titled "Optical emission" will verify this increased chlorine concentration at high $\mathrm{BCl}_{3}$ flows.

\section{$X$-ray photoelectron spectroscopy surface analysis}

$\mathrm{X}$-ray photoelectron spectroscopy (XPS) was used to determine the composition of the reaction surface layer that formed on the InP during etching. The analysis was performed ex situ on samples etched at three different oxygen concentrations: (1) without oxygen, (2) dilute oxygen addition, and (3) excess oxygen addition. The dilute oxygen addition and the excess oxygen addition consisted of $9 \%$ and $43 \%$ oxygen added to the flow mixture, respectively. The etch parameters for the sample etched without oxygen were flow rates of $12 \mathrm{std} . \mathrm{cm}^{3} \mathrm{BCl}_{3}$ and $8 \mathrm{std} . \mathrm{cm}^{3}$ argon, a power of 90 $\mathrm{W}$, a pressure of $40 \mathrm{mtorr}$, and a temperature of $250^{\circ} \mathrm{C}$. The sample etched using dilute oxygen used the identical etch parameters as the sample without oxygen, except that $2 \mathrm{std} . \mathrm{cm}^{3}$ oxygen ( $9 \%$ ) was added to the gas flow. The last sample contained excess oxygen of $15 \mathrm{std} . \mathrm{cm}^{3}$ or $43 \%$ added to the flow mixture. The atomic concentration was determined through integration of the corresponding elemental peaks and is listed below in Table 1.

The analysis of the spectra for these different samples yielded several significant differences. First, the sample etched without oxygen contained a boron peak at $187 \mathrm{eV}$, which after peak integration, yielded an atomic concentration of more than $20 \%$ boron (Walls, 1989). This surface analysis was performed on wafers etched in the RIE and then transferred to the XPS chamber. We suspect that nearly 10 to $15 \%$ carbon and oxygen contamination took place from exposure to the atmosphere during wafer transfer. This was confirmed by using an unetched control sample. The sample

Table 1. InP XPS Data (Atomic Concentration, \%)

\begin{tabular}{lccc}
\hline Element & $\begin{array}{c}\text { No Oxygen } \\
\left(0 \% \mathrm{O}_{2}\right)\end{array}$ & $\begin{array}{c}\text { Dilute } \mathrm{O}_{2} \\
\left(9 \% \mathrm{O}_{2}\right)\end{array}$ & $\begin{array}{c}\text { Excess } \mathrm{O}_{2} \\
\left(43 \% \mathrm{O}_{2}\right)\end{array}$ \\
\hline $\mathrm{In} 3 \mathrm{D}_{5 / 2}$ & 10 & 13 & 11 \\
$\mathrm{P} 2 \mathrm{P}_{3 / 2}$ & 11 & 17 & 8 \\
$\mathrm{O} 1 \mathrm{~S}_{1 / 2}$ & 28 & 38 & 39 \\
$\mathrm{C} 1 \mathrm{~S}_{1 / 2}$ & 21 & 30 & 19 \\
$\mathrm{Cl} 2 \mathrm{P}_{1 / 2}$ & 7 & 2 & 8 \\
$\mathrm{~B} 1 \mathrm{~S}_{1 / 2}$ & 23 & 0 & 15 \\
\hline
\end{tabular}


etched with dilute oxygen did not contain any boron on the surface but did contain additional oxygen on the surface. Therefore, the addition of dilute amounts of oxygen to the gas mixture increased etch rates by scavenging and removing boron from the InP surface. Finally, the sample etched with excess oxygen contained both boron and oxygen at appreciable amounts, which indicated the presence of boron oxide. The chlorine concentration for all these samples was low due to the high volatility of indium chlorides at $250^{\circ} \mathrm{C}$.

\section{Optical emission}

The changes in the gas-phase chemistry also contributed to the etch-rate enhancement taking place when oxygen was added to the gas flow. Optical emission spectroscopy was used to monitor the atomic chlorine intensity. This analysis utilizes the technique of actinometry, where a comparison of the intensity for an emission line for an active species to an emission line for an inert species can be made (Coburn and Chen, 1980). The concentration of the inert species, which is usually argon, can be assumed constant if the power and pressure are constant. In our experiments, the active species was chlorine and the inert species was argon. The intensity ratio is shown in the following equation:

$$
I(\mathrm{Cl}) / I(\mathrm{Ar})=K[\mathrm{Cl}] /[\mathrm{Ar}]
$$

where $I(\mathrm{Cl}) / I(\mathrm{Ar})=$ intensity ratio of chlorine to argon, $[\mathrm{Cl}] / \mathrm{Ar}]=$ chlorine to argon atomic concentration ratio, and $K=$ proportionality constant. Because argon is an inert gas and the argon flow rate remained constant in our experiments, the $[\mathrm{Ar}]$ intensity was assumed to be constant. Therefore, the chlorine atomic concentration was proportional to $I[\mathrm{Cl}] / I[\mathrm{Ar}]$. The emission lines of $836.4 \mathrm{~nm}$ for chlorine and $811 \mathrm{~nm}$ for argon were monitored for the flow system of 15 $\operatorname{sccm} \mathbf{B C l}_{3}$ and $5 \mathrm{sccm} \mathrm{Ar}$ at different oxygen flow rates. The actual spectra for two different oxygen flows are shown in Figure 6, with both curves superimposed upon each other. As Figure 6 shows, the addition of oxygen causes a dramatic increase in the chlorine intensity at $837 \mathrm{~nm}$. The argon intensity was nearly constant with oxygen addition. The intensity ratio, $I[\mathrm{Cl}] / I[\mathrm{Ar}]$ is plotted in Figure 7 as a function of percent of oxygen in the gas flow. Figure 7 also shows the $\operatorname{InP}$ etch rate at $250^{\circ} \mathrm{C}$ as a function of oxygen flow for the same plasma conditions. The general shape of the intensity ratio follows the shape of the etch-rate curve with the oxygen addition. The explanation for this trend is that the etch rate increases as the available chlorine increases. At high temperatures the indium chlorides are volatile, and with low oxygen additions (less than $40 \%$ ), an increase in chlorine emission intensity allowed for the corresponding increase in etch rates. At higher oxygen flow rates (greater than $40 \%$ ), both the etch rate and the chlorine concentration decrease. In this regime, boron oxychloride $\mathrm{B}_{3} \mathrm{Cl}_{3} \mathrm{O}_{3(g)}$ formation can take place, which scavenges the chlorine from the plasma. The drop of the chlorine intensity may also be due to a quenching or dilution effect due to the high oxygen flow rates used. The decrease in the etch rate at high oxygen concentrations is due to the formation of boron oxide as was previously discussed.

In summary, at low oxygen flows the etch rate increased due to an increase in the atomic chlorine concentration and

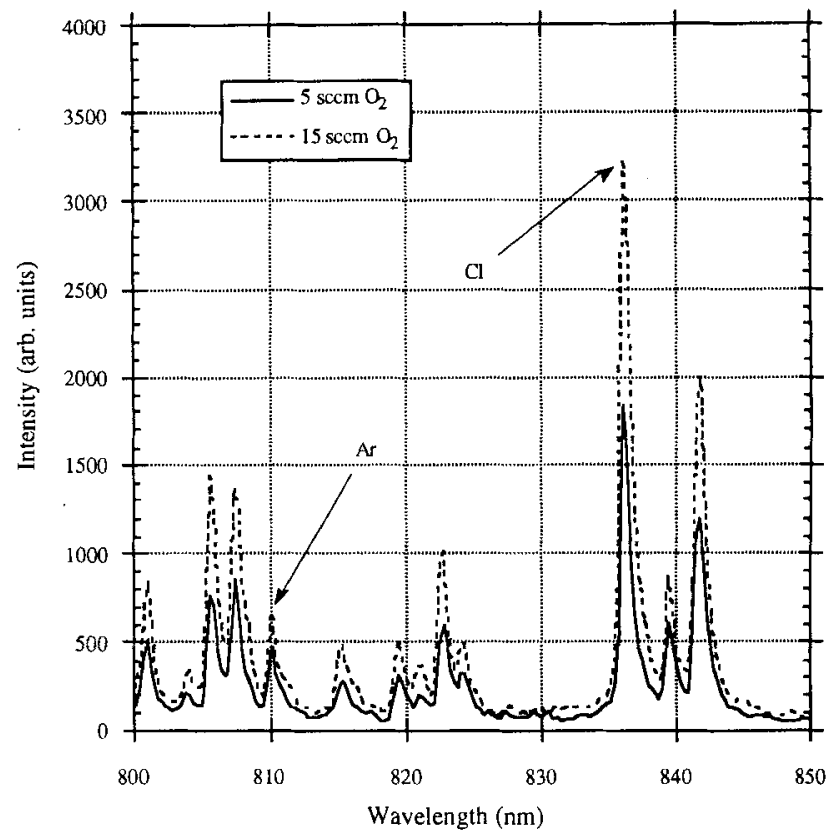

Figure 6. Optical emission spectra for $\mathrm{BCl}_{3}$ and argon for two different oxygen flows added.

the removal of boron from the InP surface. At high oxygen flow rates the etch rate decreased because of the decrease in the atomic chlorine concentration due to the formation of boron oxychlorides in the gas phase and the formation of solid boron oxide on the surface.

\section{Profile and morphology}

The morphology of the etched InP profiles exhibited a smooth to rough transition in the temperature range of $180-200^{\circ} \mathrm{C}$. At these temperatures chemical etching becomes dominant and the etch rate begins to increase significantly with temperature as was shown in the Arrhenius plots in Fig.

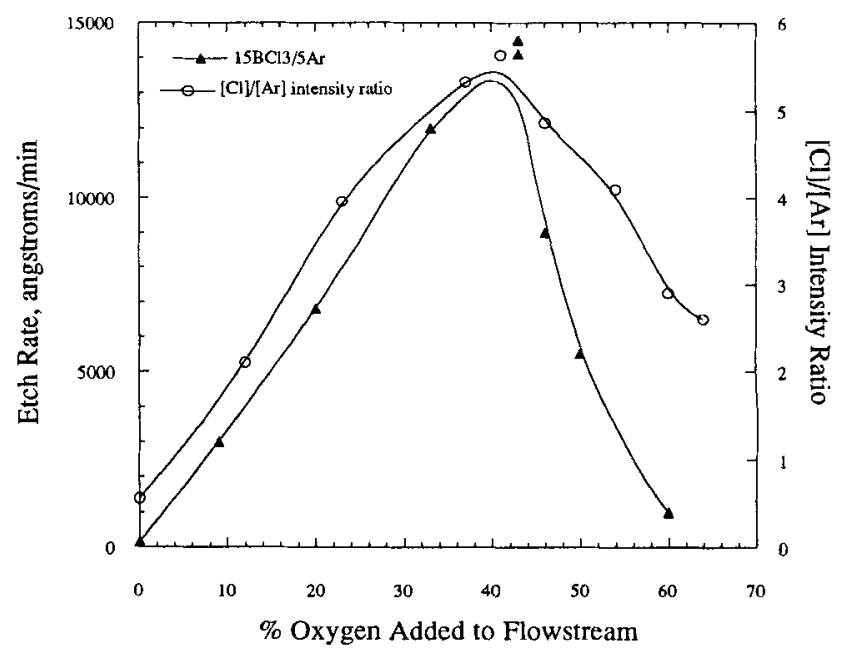

Figure 7. Comparison of InP etch rate and chlorine intensity as a function of oxygen addition.

Etching performed at $250^{\circ} \mathrm{C}$. 


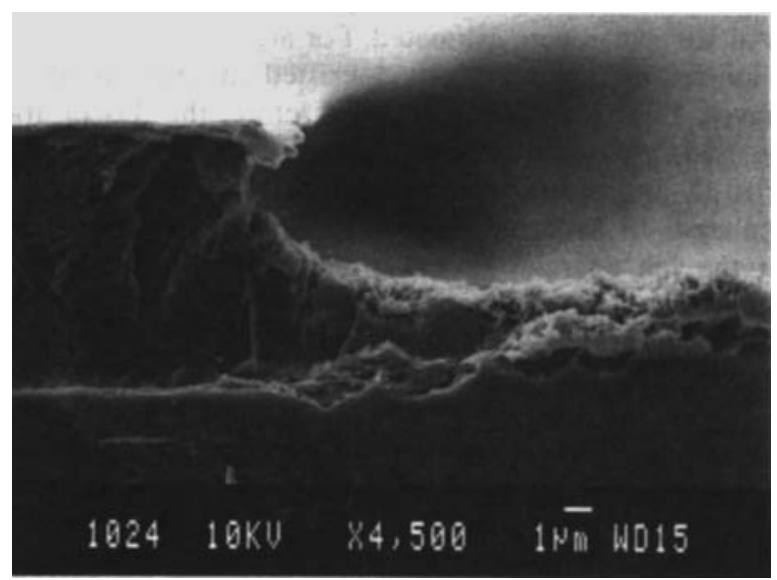

Figure 8. SEM photo for InP etched at $250^{\circ} \mathrm{C}$ with 15 std. $\mathrm{cm}^{3} \mathrm{BCl}_{3}, 5$ std. $\mathrm{cm}^{3} \mathrm{Ar}, 10$ std. $\mathrm{cm}^{3} \mathrm{O}_{2}$ at 40 mtorr and $90 \mathrm{~W}$.

ures 3 and 4 . Figure 8 shows a SEM photograph for an etch at $250^{\circ} \mathrm{C}$ using the RIE conditions of $15 \mathrm{std} . \mathrm{cm}^{3} \mathrm{BCl}_{3}, 5 \mathrm{std}$. $\mathrm{cm}^{3} \mathrm{Ar}$, and $10 \mathrm{std} . \mathrm{cm}^{3} \mathrm{O}_{2}$, power of $90 \mathrm{~W}$ and pressure of 40 mtorr. One observes in this micrograph that there is significant undercutting at low ion energies because chemical etching was dominant at these conditions and the etch rate at these conditions was near $8,000 \AA / \mathrm{min}$. At higher ion energies the profile became more anisotropic. At temperatures below $200^{\circ} \mathrm{C}$ anisotropic etching was obtained as seen in the SEM photo for a wafer temperature of $170^{\circ} \mathrm{C}$ shown in Figure 9. The conditions for this etch were flows of $12 \mathrm{std} . \mathrm{cm}^{3}$ $\mathrm{BCl}_{3}, 8 \mathrm{std} . \mathrm{cm}^{3} \mathrm{Ar}, 4 \mathrm{std} . \mathrm{cm}^{3} \mathrm{O}_{2}$ and a pressure of $30 \mathrm{mtorr}$, and a RF power of $150 \mathrm{~W}$. The etch rate at this condition was low at only $800 \AA / \mathrm{min}$, and physical etching was the dominant etching mechanism.

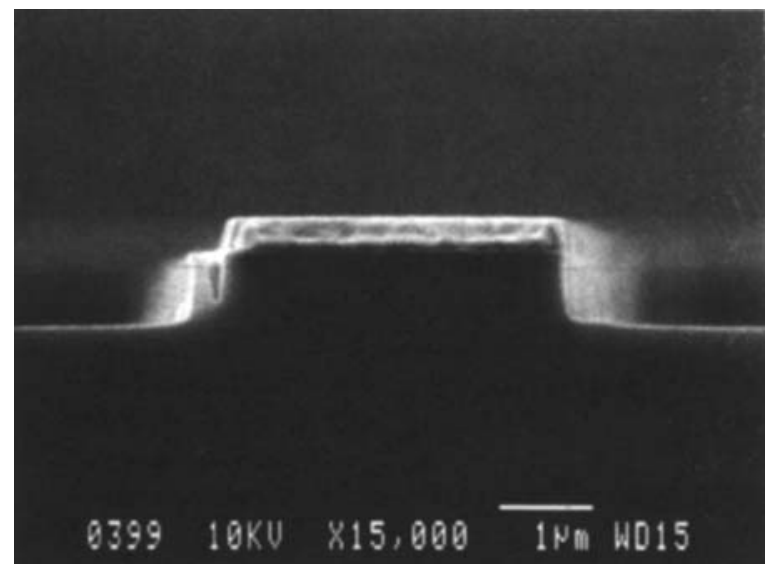

Figure 9. SEM for InP etched at $170^{\circ} \mathrm{C}$ with $12 \mathrm{std} . \mathrm{cm}^{3}$ $\mathrm{BCl}_{3}, 8$ std. $\mathrm{cm}^{3} \mathrm{Ar}, 4$ std. $\mathrm{cm}^{3} \mathrm{O}_{2}$ at 30 mtorr and $150 \mathrm{~W}$.

\section{High-Temperature Kinetic Model Introduction}

A kinetic mechanism for the reactive ion etching of InP in a $\mathrm{BCl}_{3}$ and argon plasma was developed for high-temperature etching. The mechanism involves the successive chlorination of indium and phosphorous to form indium trichloride and phosphorous trichloride, which are the reaction products. The phosphorous chlorides are high-vapor-pressure solids, and therefore the system can be viewed as a one-component system (indium).

A model of the experimental reactive-ion etching behavior was developed that is based on the elementary reaction steps taking place at the surface (surface reaction and thermal and sputter desorption). Argon ion bombardment was included in the model to account for the sputter desorption of the indium trichloride. The kinetic model was used to predict the functionality of the rate of etching. The model was simplified to include only neutral and ion components. Scattering in the bulk plasma such as gas-phase collisions was neglected as was surface charging. Changes in morphology were also not included; neither was the effect of oxygen on the surface. By making approximations about the ion and neutral fluxes, a rate law was developed containing the terms of argon ion flux and chlorine neutral flux. Comparison of the rate law with experimental results was made for high-temperature etching.

\section{Mechanism}

At high temperatures, the indium trichloride is removed by sublimation and ion bombardment. The XPS showed that there were low indium and chlorine concentrations on the InP wafer surface, which seems to indicate that the $\mathrm{InCl}$ formation step is rate limiting. At high temperatures, the chemical regime is dominant. The high-temperature etching mechanism is presented below in reactions 3 to 7 .

Reaction sequence:

$$
\begin{gathered}
\mathrm{Cl}_{(g)}+\operatorname{InP} \stackrel{k_{1}}{\longrightarrow} \operatorname{InCl}_{(\mathrm{ads})}+\mathrm{P} \\
\mathrm{Cl}_{(g)}+\mathrm{InCl}_{(\mathrm{ads})} \stackrel{k_{2}}{\longrightarrow} \mathrm{InCl}_{2(\mathrm{ads})} \\
\mathrm{Cl}_{(g)}+\mathrm{InCl}_{2} \stackrel{k_{3}}{\longrightarrow} \mathrm{InCl}_{3(\mathrm{ads})} \\
\mathrm{InCl}_{3(\mathrm{ads})}+\stackrel{k_{4}}{\longrightarrow} \mathrm{InCl}_{3(g)} \\
\mathrm{InCl}_{3(\mathrm{ads})}+\mathrm{Ar}^{+} \stackrel{k_{a}}{\longrightarrow} \mathrm{InCl}_{3(g)}+\mathrm{Ar}^{+}
\end{gathered}
$$

The Arrhenius plots that are presented in Figures 2 and 3 indicated that there are two etching regimes for InP shown by the two linear portions in the plots. At low temperatures (less than $200^{\circ} \mathrm{C}$ ) the removal of indium chlorides limits the etch rate. At temperatures above $220^{\circ} \mathrm{C}$, the indium chlorides are more easily desorbed and the rate-limiting step is a surface reaction.

Because the removal of indium chloride is easily accomplished at high temperatures, one of the surface reactions was chosen as the rate-limiting step. By using the previous XPS results it was found that the surface contained low concentrations of indium and chlorine. Therefore, it was determined that the $\mathrm{InCl}$ formation step was the rate-limiting step and a rate law was determined for this reaction. An analo- 
gous study to our InP system is the silicon etching with fluorine where the SiF formation step was found to be the slowest reaction when etching chemically (Plumb and Ryan, 1985, 1986). The rate law equation for the $\mathrm{InCl}$ formation can be written as $R_{\mathrm{InCl}}^{f}$ and is shown in Eq. 8 .

$$
R_{\mathrm{inCl}}^{f}=k_{1}[\mathrm{Cl}][\mathrm{InP}]
$$

The net rates of formation for $\mathrm{InCl}, \mathrm{InCl}_{2}$, and $\mathrm{InCl}_{3}$ are given by Eqs. 9, 11, and 13, respectively. Because we are etching at steady state, the net rates of formation of these intermediates are zero, and the rate equations are solved to give the fractional surface coverage for $\mathrm{InCl}$ and $\mathrm{InCl}_{2}$ in Eqs. 10 and 12 , respectively.

$$
\begin{gathered}
R_{\mathrm{InCl}}=k_{1}[\mathrm{Cl}][\mathrm{InP}]-k_{2}[\mathrm{Cl}][\mathrm{InCl}]=0 \\
{[\mathrm{InCl}]=\left(k_{1} / k_{2}\right)[\mathrm{InP}]} \\
R_{\mathrm{InCl} 2}=k_{2}[\mathrm{InCl}][\mathrm{Cl}]-k_{3}\left[\mathrm{InCl}_{2}\right][\mathrm{Cl}]=0 \\
{\left[\mathrm{InCl}_{2}\right]=\left(k_{2} / k_{3}\right)[\mathrm{InCl}]} \\
R_{\mathrm{InCl} 3}=k_{3}[\mathrm{Cl}]\left[\mathrm{InCl}_{2}\right]-k_{4}\left[\mathrm{InCl}_{3}\right]-k_{a}[\mathrm{Ar}]\left[\mathrm{InCl}_{3}\right]=0 .
\end{gathered}
$$

For the $\mathrm{InCl}_{3}$ formation reaction, in Eq. 13, the first term on the righthand side represents the formation of indium trichoride, with the second and third terms representing $\mathrm{InCl}_{3}$ loss through desorption and sputtering. Solving Eq. 13 for the fractional coverage of $\mathrm{InCl}_{3}$ and then using Eqs. 10 and 12, we obtain Eqs. 14 and 15. By using a site balance that the sum of all sites equals one $\left([\mathrm{InP}]+[\mathrm{InCl}]+\left[\mathrm{InCl}_{2}\right]+\left[\mathrm{InCl}_{3}\right]=\right.$ 1), the expression for [InP] is obtained in Eq. 16, which is substituted into Eq. 8 to give the etch rate equation in 17. Equation 17 is algebraically simplified to give Eq. 18 .

$$
\begin{gathered}
{\left[\mathrm{InCl}_{3}\right]=\frac{k_{3}\left[\mathrm{InCl}_{2}\right][\mathrm{Cl}]}{k_{4}+k_{a}[\mathrm{Ar}]}} \\
{\left[\mathrm{InCl}_{3}\right]=\frac{k_{1}[\mathrm{InP}][\mathrm{Cl}]}{k_{4}+k_{a}[\mathrm{Ar}]}} \\
R_{\mathrm{InCl}}^{f}=\frac{1}{1+k_{1} / k_{2}+k_{1} / k_{3}+\frac{k_{1}[\mathrm{Cl}]}{k_{4}+k_{a}[\mathrm{Ar}]}} \\
R_{\mathrm{etch}}=\frac{\left[k_{1} / k_{2}+k_{1} / k_{3}+\frac{k_{1}[\mathrm{Cl}]}{k_{4}+k_{a}[\mathrm{Ar}]}\right.}{\left(1 / k_{1}+1 / k_{2}+1 / k_{3}\right)\left(k_{4}+k_{a}[\mathrm{Ar}]\right)+[\mathrm{Cl}]} .
\end{gathered}
$$

The rate equation (Eq. 18) shows that at low chlorine neutral and argon ion concentrations, the etch rate is linear with the chlorine concentration. In order to check and verify the overall rate law with experimental data, it is necessary to find both the $[\mathrm{Cl}$ ] and [Ar] terms from the etch rate data. Kinetic gas theory was used to calculate these specific fluxes from the data (Adamson, 1982; McNevin, 1984). For the $\mathrm{BCl}_{3}$ and ar- gon gas mixtures used in these experiments, chlorine flux values of $10^{15} / \mathrm{cm}^{2}$ s were estimated. For argon, we assumed that an ionization fraction of $10^{-4}$ existed at these conditions (Graves, 1989; McNevin, 1984). Therefore, the flux of argon ions used in our modeling experiments was approximated by [Ar] $10^{-4}$, and values on the order of $10^{14}$ ions $/ \mathrm{cm}^{2} \cdot \mathrm{s}$ were calculated. In order to simplify the model, it was assumed that the ion energies (ion distribution) were constant and therefore the argon ions produced had constant ion energy and directional angle. Because the power and pressure were constant in these experiments, the assumption of constant argon ion energy is valid.

Oxygen was added to the mixture of $\mathrm{BCl}_{3}$ and argon gas to increase the chlorine neutral concentration. The data for the chlorine concentration were obtained from optical emission, as shown in Figure 7 . The term $\mathrm{Cl}^{*}$ represents the corrected chlorine flux, which compensates for the oxygen used to remove boron from the wafer surface, thereby reducing the chlorine flux. The pressure and power for the optical emission analysis was kept constant. As a result, the assumption of chlorine neutral concentration being proportional to the chlorine emission intensity is reasonable, since only chemical effects (oxygen addition) induced the chlorine intensity to increase. The model does not include the higher oxygen flow regime where boron oxide formation takes place.

The etch rate vs. chlorine concentration for different chlorine/argon mixtures is shown in Figure 10. As one can see a linear relationship exists. The data also shows a slight argon dependence, and this argon dependence is probably due to the fact that argon sputtering plays a role in InP etching even at high temperatures.

The rate law for the etching of InP at high temperatures is given in Eq. 18 and can be simplified by allowing the rate constants to be lumped together. In Eq. 19, the simplified rate equation is shown with the definition of the rate constants $k_{t}, k_{t / a}$, and $k_{4 / a}$ given in Eqs. 20 to 22 , respectively.

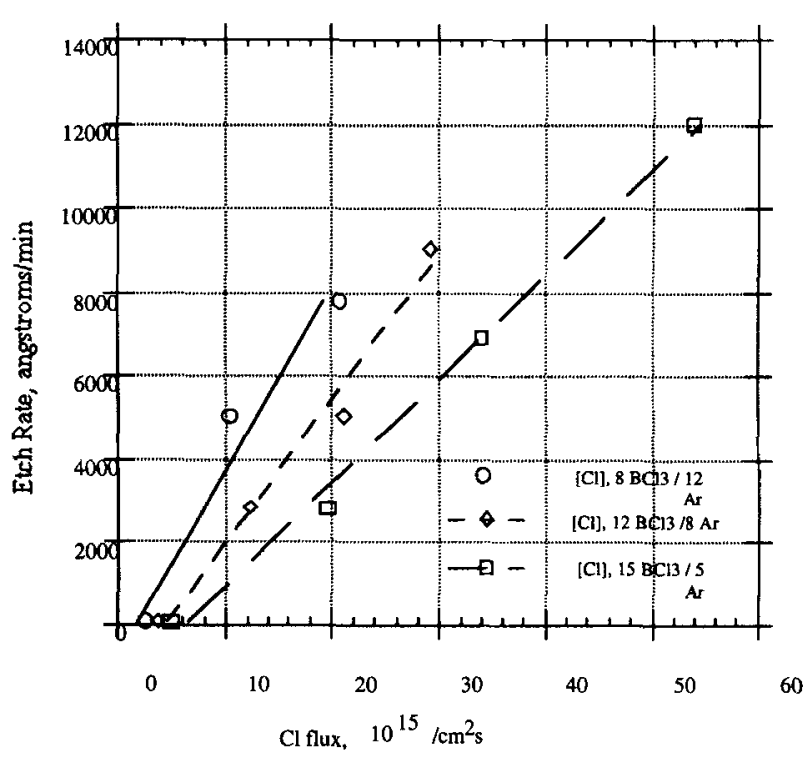

Figure 10. Etch rate as a function of $\mathrm{Cl}$ flux for different flow conditions. 


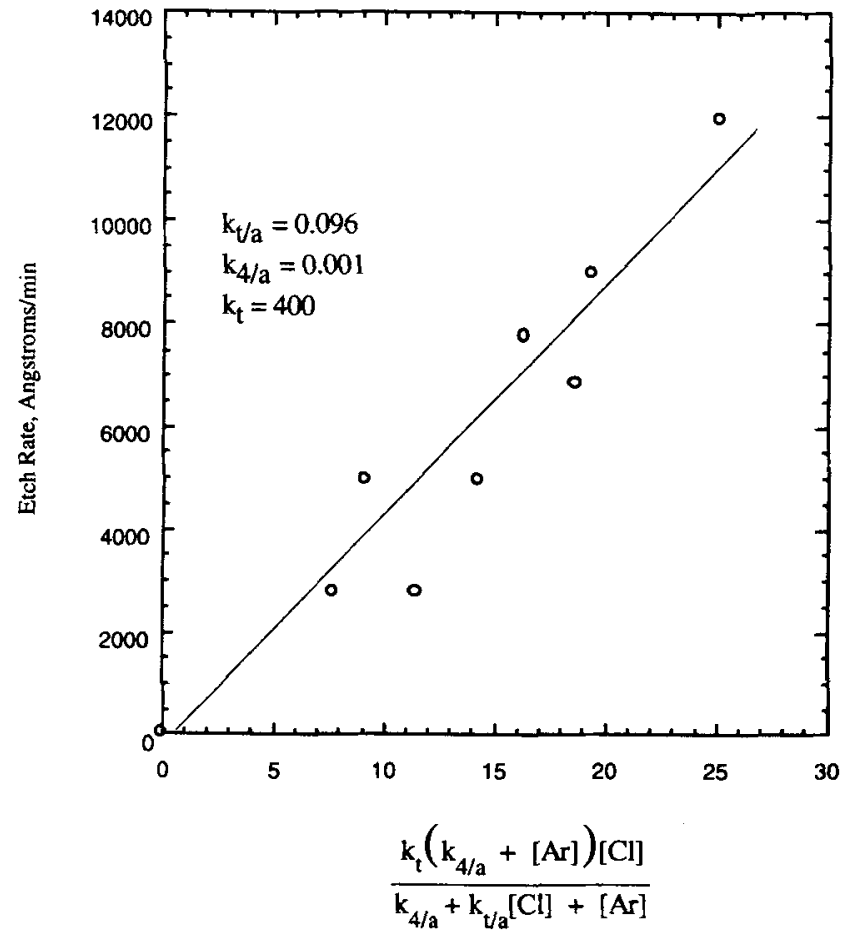

Figure 11. Experimental data plotted in the form of the rate law.

$$
\begin{aligned}
R_{\mathrm{etch}} & =\frac{k_{t}\left(k_{4 / a}+[\mathrm{Ar}]\right)[\mathrm{Cl}]}{k_{4 / a}+k_{t / a}[\mathrm{Cl}]+[\mathrm{Ar}]} \\
k_{t} & =\frac{1}{\left(1 / k_{1}+1 / k_{2}+1 / k_{3}\right)} \\
k_{t / a} & =\frac{k_{t}}{k_{a}} \\
k_{4 / a} & =\frac{k_{4}}{k_{a}} .
\end{aligned}
$$

In Figure 11, the form of Eq. 19 is plotted vs. the etch rate. This figure was obtained by successive least-squares fitting, and the values obtained for the rate constants were $k_{t / a}=$ $0.096, k_{4 / a}=0.001$, and $k_{t}=400$. The model is valid for the constant pressure and power regime stated. New actinometry results would be required for different power and pressure regimes.

The low value of $k_{t / a}$ indicates that $k_{a}$ is larger than $k_{4}$, indicating that sputtering is important at high temperatures. Although the argon ions participate in sputtering reactions at the wafer surface, the gas-phase reactions that the ions are involved in are equally important. Without argon, the glow discharge would be difficult to sustain, and the chlorine neutral concentration would decrease since the argon ion impact dissociation reactions with $\mathrm{BCl}_{3}$ would not take place.

\section{Conclusions}

The reactive ion etching of $\mathrm{InP}$ at high temperatures was studied using mixtures of $\mathrm{BCl}_{3}, \mathrm{Ar}$, and $\mathrm{O}_{2}$. There are two etching regimes that are a function of temperature. Below $150^{\circ} \mathrm{C}$, the removal of indium chlorides limits the etch rate, and above $200^{\circ} \mathrm{C}$, the mechanism appears to be surface-reaction limited. The addition of oxygen increased the etch rate by removing boron species from the InP surface and by increasing the chlorine neutral concentration in the gas-phase. At high oxygen flows the etch rate decreased due to the formation of boron oxide on the InP surface. It was possible to obtain vertical etch structures using this system at temperatures below $180^{\circ} \mathrm{C}$ with high ion energies. For InP, a rate law for etching InP was developed in terms of the chlorine-neutral and argon-ion flux. After being determined this rate law was compared with experimental etch-rate data. It compared favorably with experimental results.

\section{Acknowledgments}

This research is supported by the U.S. Army Research Office. We would like to thank Professor George Haddad, the program director, for his support throughout this work. Also, thanks to Hal Estry for help in performing the XPS experiments and Jerry Pender for help with the optical emission work.

\section{Literature Cited}

Adamson, A. W., Physical Chemistry of Surfaces, 4th ed., Wiley, New York, 520 (1982).

Coburn, J. W., and M. Chen, "Optical Emission Spectroscopy of Reactive Plasmas: A Method for Correlating Emission Intensity to Reactive Particle Density," J. Appl. Phys., 51, 3134 (1980).

Contolini, R. J., "The Temperature Dependence of the Etch Rates of GaAs, AlGaAs, InP, and Masking Materials in a Chlorine Plasma," J. Electrochem. Soc., 135(4), 929 (1988).

Cooperman, S. S., H. K. Choi, H. H. Sawin, and D. F. Kolesar, "Reactive Ion Etching of $\mathrm{GaAs}$ and $\mathrm{AlGaAs}$ in a $\mathrm{BCl}_{3}$-Ar Discharge," J. Vac. Sci. Technol. B, 7(1), 41 (1989).

Dean, J. A., Langes Handbook of Chemistry, McGraw-Hill, New York (1985).

Donnelly, V. M., D. L. Flamm, C. W. Tu, and D. E. Ibbotson, "Temperature Dependence of InP and GaAs Etching in a Chlorine Plasma," J. Electrochem. Soc., 129(7), 2533 (1982).

Gottscho, R., G. R. Smolinsky, and R. H. Burton, "Carbon Tetrachloride Plasma Etching of GaAs and InP: A Kinetic Study Utilizing Nonperturbative Optical Techniques," J. Appl. Phys., 52(8), 5908 (1982).

Graves, D. B., "Plasma Processing in Microelectronics Manufacturing," AIChE J., 35, 1 (1989).

Hayes, T. R., M. A. Dreisbach, P. M. Thomas, W. C. DautremontSmith, and L. A. Helmbrook, "Reactive Ion Etching of InP Using $\mathrm{CH}_{4} / \mathrm{H}_{2}$ Mixtures: Mechanisms of Etching and Anisotropy," $J$. Vac. Sci. Technol. B, 7(5), 1130 (1988).

Hayes, T. R., M. A. Dreisbach, P. M. Thomas, W. C. DautremontSmith, and L. A. Heimbrook, "Reactive Ion Etching of InP Using $\mathrm{CH}_{4} / \mathrm{H}_{2}$ Mixtures: Mechanisms of Etching and Anisotropy," $J$. Vac. Sci. Technol. B, 7, 1130 (1989).

Hess, D. W., "Aluminum Reactive Ion Etching with $\mathrm{BCl}_{3} / \mathrm{Cl}_{2} \mathrm{Mix}$ tures," Plasma Chem. Plasma Proc., 2, 141 (1982).

McNevin, S. C., and G. E. Becker, " $\mathrm{CF}_{4} /$ Silicon Surface Reactions: Evidence of Parallel Etching Mechanisms from Modulated Ion Beam Studies," J. Vac. Sci. Technol. B, 2, 27 (1984).

Plumb, I. C., and K. R. Ryan, "Free Radical Chemistry in the Plasma Etching Process," Int. Symp. Plasma Chem., 3, 960, Eindhoven Univ., Eindhoven, Neth. (1985).

Plumb, I. C. and K. R. Ryan, "A Model for the Etching of Silicon in Tetrafluoromethane Plasmas: Comparison with Experiment Measurements," Plasma Chem. Plasma Proc., 6, 231 (1986).

Sonek, G. J., and J. M. Ballantyne, "Reactive Ion Etching of GaAs Using $\mathrm{BCl}_{3}$, "J. Vac. Sci. Technol. B, 2, 653 (1984).

Walls, J. M., Methods of Surface Analysis: Techniques and Applications, Cambridge Univ. Press, Cambridge, England (1989).

Manuscript received Aug. 9, 1993, and revision received May 16, 1994. 